\title{
Evaluation of Layered Graphene Prepared via Hydroxylation of Potassium-Graphite Intercalation Compounds
}

\author{
Takuya Wada, ${ }^{1,2}$ Takuya Yasutake, ${ }^{1}$ Akira Nakasuga, \\ Taro Kinumoto, ${ }^{1}$ Tomoki Tsumura, ${ }^{1}$ and Masahiro Toyoda ${ }^{1}$ \\ ${ }^{1}$ Department of Applied Chemistry, Faculty of Engineering, Oita University, 700 Dannoharu, Oita 870-1192, Japan \\ ${ }^{2}$ High Strength Polymer Laboratory, High Performance Plastics Company, Sekisui Chemical Co. Ltd., 2-1 Hyakuyama, Shimamoto-cho, \\ Mishima-gun, Osaka 618-0021, Japan
}

Correspondence should be addressed to Takuya Wada; wada012@sekisui.com

Received 7 April 2014; Revised 6 June 2014; Accepted 7 June 2014; Published 3 August 2014

Academic Editor: Naoki Kishi

Copyright (C) 2014 Takuya Wada et al. This is an open access article distributed under the Creative Commons Attribution License, which permits unrestricted use, distribution, and reproduction in any medium, provided the original work is properly cited.

Layered graphene was prepared via the hydroxylation of potassium-graphite intercalation compound $\left(\mathrm{KC}_{8}\right)$ produced from exfoliated graphite flake powder. When a small amount of water was dropped onto the $\mathrm{KC}_{8}$ in an oxygen-free atmosphere, the stage structure of the intercalation compounds was broken, and agglomerated graphene was obtained. Sonication of this agglomerated graphene in buffered water containing sodium dodecyl sulfate followed by rinsing with hot water yielded gray samples. Using scanning electron microscopy, X-ray diffraction analysis, and Raman spectroscopy, the gray samples were determined to be composed of a few layers of graphene with an area of $20-100 \mu \mathrm{m}^{2}$ and thickness of $1.7 \mathrm{~nm}$. They were thinner than those obtained when starting with natural graphite.

\section{Introduction}

Graphene has been developed recently, and large area graphene is made using chemical vapor deposition (CVD). One of the potential uses for graphene is in transmissive electrodes. However, it is difficult to construct a circuit directly on polymer and glass substrates using the CVD. Therefore it is necessary to transfer graphene prepared on a copper substrate to polymeric surfaces. This transcription process involves several different procedures, and many potential problems, such as the introduction of graphene defects, may occur [1].

Another method for the production of graphene involves the exfoliation of graphene layer from graphite, which is referred to as Hummer's method. In this case, graphite is oxidized and then graphene layers are exfoliated from the graphite using different methods, such as ultrasonic techniques $[2,3]$. Using this approach, it is possible to build a circuit electrode by coating the substrate with a dispersion of oxidized graphene, followed by drying. However, many sites are converted from $\mathrm{sp}^{2}$ to $\mathrm{sp}^{3}$ structures during the oxidation and exfoliation processes. Consequently, a reduction process is subsequently required to reduce the $\mathrm{sp}^{3}$ structures. Not all of the $\mathrm{sp}^{3}$ carbons are reduced during this process, however, and some $\mathrm{sp}^{3}$ structures remain. Graphene containing $\mathrm{sp}^{3}$ carbons has poor conductivity, and therefore, a technique for exfoliation of graphene without using an oxidation process is required [4].

The compound $\mathrm{KC}_{8}$, a potassium-graphite intercalated compound with a first-stage structure, has been established and reported in the literature. $\mathrm{KC}_{8}$ is produced using the twobulb method, which is a gas phase method $[5,6]$. Because it is unstable in air, the $\mathrm{KC}_{8}$ first-stage structure gradually changes to a second-stage structure (referred to as $\mathrm{KC}_{24}$ ) or a third stage structure [7].

The synthesis of graphene from natural graphite powder via $\mathrm{KC}_{8}$ without conversion to graphite oxide has been attempted [8]. However, intermediate products comprising agglomerated graphene layers using this method indicate $\mathrm{X}$-ray diffraction (XRD) patterns of graphite, and it was difficult to reduce the peeks of graphite by using ultrasonic treatment in water buffer. In this study, synthesis of graphene 


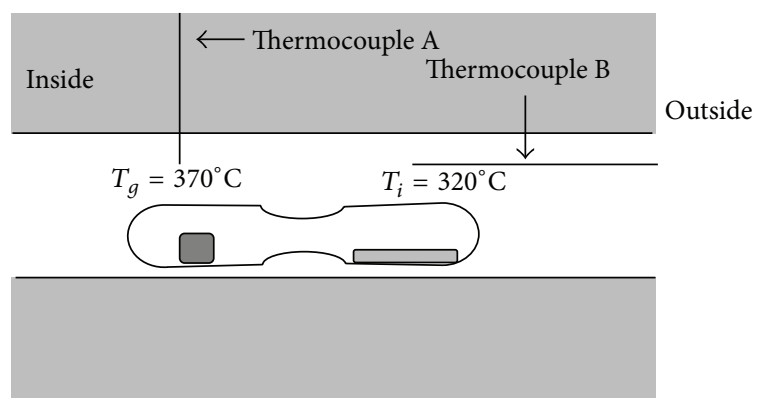

FIGURE 1: Image of inside of furnace.

from the graphite intercalation compound $\mathrm{KC}_{8}$ was prepared from exfoliated graphite as a host carbon material for the purpose of getting many thinner graphene layers. In addition, stable exfoliation using a surfactant (sodium dodecyl sulfate, SDS) for prevention of the aggregation and restacking of the graphene is discussed.

\section{Materials and Methods}

2.1. Preparation of $\mathrm{KC}_{8}$. K-GIC $\left(\mathrm{KC}_{8}\right)$ with a first-stage structure was prepared using the two-bulb method. Potassium (Grade KK02GB, 1.5 g, KOJUNDO CHEMICAL LABORATORY CO. LTD.) was added to exfoliated graphite powder (Grade PF8, 0.1 g, Toyo Tanso Co. Ltd.) in a glass ampoule. The potassium in the ampoule was repeatedly purified, and then the ampoule was sealed and placed in a tubular furnace (Figure 1) at $370^{\circ} \mathrm{C}$, the glass transition temperature of graphite $\left(T_{g}\right)$. This glass ampoule was then cooled to $320^{\circ} \mathrm{C}$ the temperature of potassium $\left(T_{i}\right)$ and maintained for $48 \mathrm{~h}$. Subsequently the glass ampoule was ejected from the furnace and cooled naturally to room temperature. The appearance of the exfoliated graphite powder was visually evaluated, and then the heat-treated glass ampoule was then placed in a glove box with a controlled dew point $<-30^{\circ} \mathrm{C}$ and an argon gas atmosphere, and a graphite intercalated compound was obtained. K-GIC is unstable in an air atmosphere because it reacts with the oxygen and moisture in the air. The prepared K-GIC (referred to as PF8-KC 8 ) was analyzed via powdered XRD (RINT-ULTIMA III, Rigaku Corporation) in an airproof sample cell under an argon atmosphere at $40 \mathrm{kV}$ with a power of $40 \mathrm{~mA}$ and a scanning speed of $5^{\circ} \mathrm{min}^{-1}$.

2.2. Hydroxylation of $\mathrm{KC}_{8}$. The hydroxylation of $\mathrm{KC}_{8}$ was performed via the addition of pure water $\left(0.05 \mathrm{~cm}^{3}\right)$ to $\mathrm{PF} 8$ $\mathrm{KC}_{8}(0.05 \mathrm{~g})$ using a syringe in a glove box filled with argon gas (oxygen concentration $<5 \mathrm{ppm}$ and dew point $<-30^{\circ} \mathrm{C}$ ). The obtained hydroxylated $\mathrm{PF} 8-\mathrm{KC}_{8}$ (referred to as PF8$\mathrm{KC}_{8}-\mathrm{H}_{2} \mathrm{O}$ ) was aggregated, as revealed by the XRD analysis performed using an air-proof sample cell under an argon atmosphere.

2.3. Dispersion of $\mathrm{PF} 8-\mathrm{KC}_{8}-\mathrm{H}_{2} \mathrm{O}$ in an SDS Water Solution. To prevent the aggregation and restacking of the exfoliated graphene layers in water, $\mathrm{PF} 8-\mathrm{KC}_{8}-\mathrm{H}_{2} \mathrm{O}(0.10 \mathrm{~g})$ was added

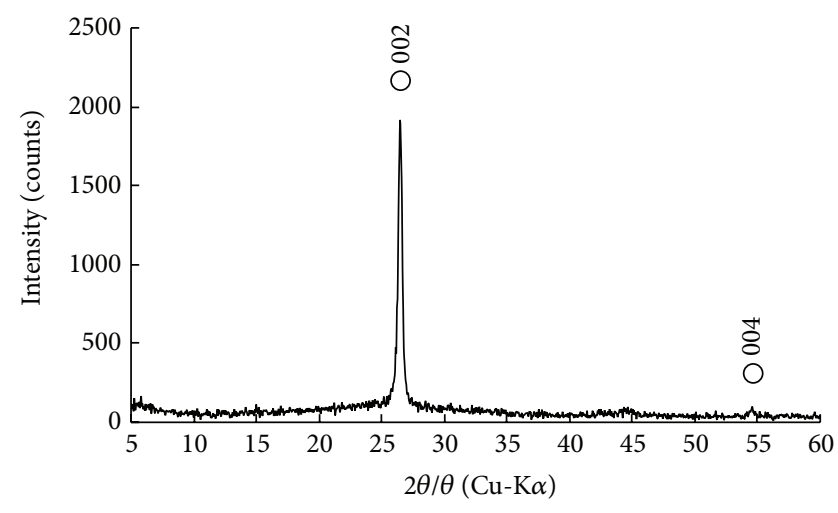

Graphite

FIGURE 2: XRD pattern of PF8 (exfoliated graphite).

to an aqueous solution $\left(20 \mathrm{~cm}^{3}\right)$ containing $3.0 \mathrm{wt} \% \mathrm{SDS}$, and the mixture was sonicated $(28 \mathrm{kHz}, 100 \mathrm{~W}, 10 \mathrm{~s})$ using an ultrasonic bath (W-113, HONDA ELECTRONICS CO., LTD.). A small amount of this sonicated sample (referred to as $\mathrm{PF} 8-\mathrm{KC}_{8}-\mathrm{H}_{2} \mathrm{O}-\mathrm{SDS}$ ) was then further diluted with water and placed on a mica cleavage plane for analysis using atomic force microscopy (AFM; VN-8010, KEYENCE Corporation).

2.4. Elimination of SDS and Water from the Exfoliated Graphene Layer via Filtration. The PF8- $\mathrm{KC}_{8}-\mathrm{H}_{2} \mathrm{O}-\mathrm{SDS}$ dispersion was filtered using a nitrocellulose membrane with a pore diameter of $3 \mu \mathrm{m}$ and then rinsed with $50^{\circ} \mathrm{C}$ water $\left(400 \mathrm{~cm}^{3}\right)$ to remove the SDS and potassium oxide as $\mathrm{KOH}$. The nitrocellulose membrane was then dried and cut into pieces to analyze the rinsed sample $\left(\mathrm{PF} 8-\mathrm{KC}_{8}-\mathrm{H}_{2} \mathrm{O}-\mathrm{SDS}\right.$ rins) using scanning electron microscopy (SEM; S-4300, JEOL Ltd.), XRD, and Raman spectroscopy (Almega XR, Thermo Fischer SCIENTIFIC). An SN100-KC $\mathrm{K}_{8}-\mathrm{H}_{2} \mathrm{O}-\mathrm{SDS}$ rins sample was prepared in a similar manner for comparing. SN100 is natural graphite powder obtained from SEC CARBON Ltd.

\section{Results and Discussion}

3.1. Preparation of $K C_{8}$. The XRD patterns of the PF8 (exfoliated graphite powder) starting material and exfoliated graphite with intercalated potassium $\left(\mathrm{PF} 8-\mathrm{KC}_{8}\right)$ prepared using the two-bulb method are shown in Figures 2 and 3, respectively. In the diffraction pattern for PF8- $\mathrm{KC}_{8}$, the peaks at $2 \theta=16.6^{\circ}, 2 \theta=21.2^{\circ}, 2 \theta=33.5^{\circ}$, and $2 \theta=45.6^{\circ}$ are the $\mathrm{KC}_{8} 004, \mathrm{KC}_{8} 101, \mathrm{KC}_{8} 008$, and $\mathrm{KC}_{8} 116$ diffraction lines, respectively. The gold color of $\mathrm{PF} 8-\mathrm{KC}_{8}$ (Figure 4(a)) also confirmed that the prepared $\mathrm{KC}_{8}$ possessed a $\mathrm{K}-\mathrm{GIC}$ first-stage structure.

3.2. Hydroxylation of $\mathrm{KC}_{8}$. A small amount of pure water was dropped onto $\mathrm{PF} 8-\mathrm{KC}_{8}$ using a syringe, and the water was absorbed by $\mathrm{PF} 8-\mathrm{KC}_{8}$ within a few seconds, resulting in a change in the color of the sample from gold to black. Figure 4(b) shows the appearance of the sample after the 


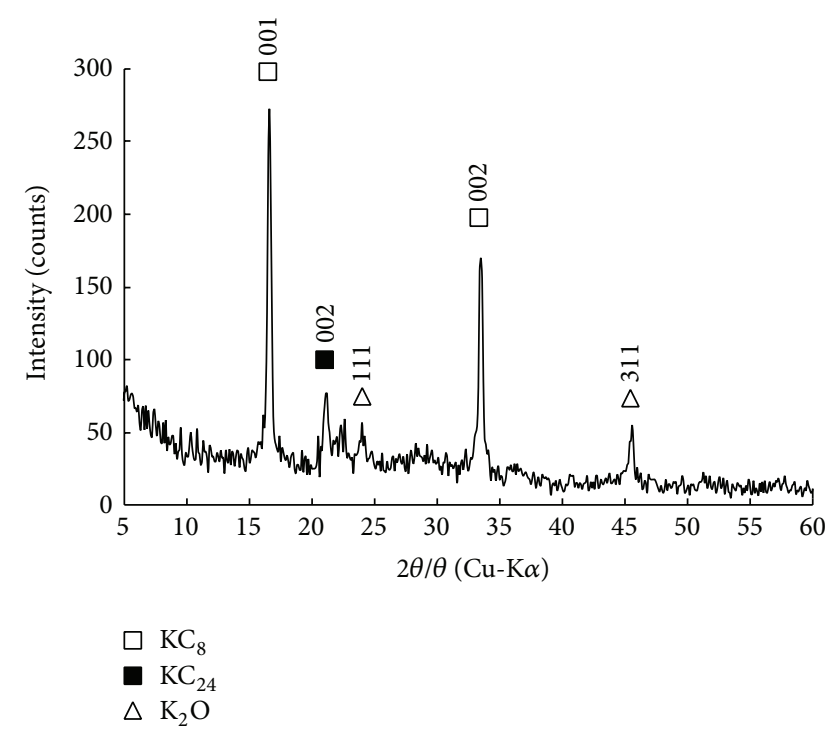

FIGURE 3: XRD pattern of PF8- $\mathrm{KC}_{8}$.

addition of water, and Figure 5(b) presents the XRD pattern of PF8- $\mathrm{KC}_{8}-\mathrm{H}_{2} \mathrm{O}$ in an argon gas atmosphere using an airproof sample cell. As observed by comparing Figures 3 and $5(\mathrm{~b})$, the peaks for PF8-KC 8 could no longer be detected in the hydroxylated sample. This result indicates that the intercalated potassium reacted with the water to generate potassium hydroxide and hydrogen gas in (1), and the $\mathrm{H}_{2}$ then degraded the stage structure, leading to the conversion of the regular layers to an amorphous structure:

$$
2 \mathrm{~K}(\mathrm{sol})+2 \mathrm{H}_{2} \mathrm{O}(\mathrm{liq}) \longrightarrow 2 \mathrm{KOH}(\mathrm{aq})+\mathrm{H}_{2} \text { (gas) } \uparrow
$$

In addition, the presence of peaks at $2 \theta=27.8^{\circ}\left(\mathrm{K}_{2} \mathrm{O}\right.$ 200 diffraction) in the diffraction pattern for $\mathrm{PF} 8-\mathrm{KC}_{8}$ $\mathrm{H}_{2} \mathrm{O}$ (Figure 5(b)) indicated that crystalline $\mathrm{K}_{2} \mathrm{O}$ was also generated. This result suggested that small amount of the oxygen in the glove box reacted with the potassium in K-GIC, as shown in

$$
4 \mathrm{~K}+\mathrm{O}_{2} \longrightarrow 2 \mathrm{~K}_{2} \mathrm{O}
$$

Notably, the graphite 002 diffraction line at $2 \theta=26.5^{\circ}$ was not detected in Figure 5(b), but it was observed for the sample prepared using natural graphite $\left(\mathrm{SN} 100-\mathrm{KC}_{8}-\mathrm{H}_{2} \mathrm{O}\right)$. This difference was subtle but important and confirmed that PF8- $\mathrm{KC}_{8}-\mathrm{H}_{2} \mathrm{O}$ possessed an amorphous graphite structure and crystalline $\mathrm{K}_{2} \mathrm{O}$.

\subsection{Dispersion of $\mathrm{PF} 8-\mathrm{KC}_{8}-\mathrm{H}_{2} \mathrm{O}$ in an SDS Water Solution} and Determination of Graphene Thickness. PF8- $\mathrm{KC}_{8}-\mathrm{H}_{2} \mathrm{O}$ was added to an aqueous $3.0 \mathrm{wt} \% \mathrm{SDS}$ solution and sonicated to disperse the graphene and disrupt any agglomerated layers.

A small amount of the $\mathrm{PF} 8-\mathrm{KC}_{8}-\mathrm{H}_{2} \mathrm{O}-\mathrm{SDS}$ sample was then diluted with additional water, placed on a mica cleavage plane, and dried at room temperature for AFM analysis. In one portion of this sample, the average thickness and maximum length were determined to be $1.7 \mathrm{~nm}$ and $5776 \mathrm{~nm}$, respectively, as shown in Figure 6. Therefore, it was concluded that a few graphene layers with an estimated interlayer distance of $0.335 \mathrm{~nm}$ were absorbed by the SDS.

3.4. Elimination of SDS and Water from the Exfoliated Graphene Layer by Filtration. The $\mathrm{PF} 8-\mathrm{KC}_{8}-\mathrm{H}_{2} \mathrm{O}-\mathrm{SDS}$ dispersion was filtered through a nitrocellulose membrane and then washed with hot water to remove SDS and potassium oxide as $\mathrm{KOH}$, as shown in

$$
2 \mathrm{~K}_{2} \mathrm{O}(\mathrm{sol})+\mathrm{H}_{2} \mathrm{O}(\mathrm{liq}) \longrightarrow 2 \mathrm{KOH}(\mathrm{aq})
$$

The membrane containing the graphene $\left(\mathrm{PF} 8-\mathrm{KC}_{8}-\mathrm{H}_{2} \mathrm{O}-\right.$ SDS-rins) was then dried and cut into pieces for analysis via SEM, XRD, and Raman spectroscopy.

A representative SEM photograph of $\mathrm{PF} 8-\mathrm{KC}_{8}-\mathrm{H}_{2} \mathrm{O}$ SDS-rins is shown in Figure 7(a), wherein it can be seen that the PF8- $\mathrm{KC}_{8}-\mathrm{H}_{2} \mathrm{O}$-SDS-rins was reflected the scabrous geometry of nitrocellulose membrane filter and appeared to be soft. From the SEM data, samples comprising a few graphene layers were estimated to be $5-20 \mu \mathrm{m}^{2}$ in area, which was in good agreement with the AFM result. Viculis et al. [9] reported that carbon nanoscrolls were obtained by adding ethanol to K-GIC, but in the present study, microsized carbon sheets were obtained by adding water. In addition, the use of SDS as an anionic surface-active agent in the water helped prevent the exfoliated graphene from forming scrolls in solution. SDS has a hydrophobic molecular chain and hydrophilic groups. It is though that the hydrophobic molecular chain adsorbed to the surfaces of the graphene layers, while the hydrophilic groups acted as water buffers [10]. Electrostatic repulsion of the hydrophilic groups in the water buffer made the graphene layer to be taut and this graphene layer settled out on the filter membrane. So the graphene layer appeared as a sheet, rather than being scrolled. The $\mathrm{SN} 100-\mathrm{KC}_{8}-\mathrm{H}_{2} \mathrm{O}$-SDS-rins sample was prepared using the same technique as that for PF8$\mathrm{KC}_{8}-\mathrm{H}_{2} \mathrm{O}$-SDS-rins sample. However, it appeared to be rigid and thick on the nitrocellulose membrane filter. Using the nitrocellulose membrane filter, large amount of sample was deposited from dispersion buffer, and many pieces of SN100$\mathrm{KC}_{8}-\mathrm{H}_{2} \mathrm{O}$-SDS-rins sample were not exfoliated (Figure 7(b)).

Next, the PF8- $\mathrm{KC}_{8}-\mathrm{H}_{2} \mathrm{O}-\mathrm{SDS}$-rins sample was analyzed by $\mathrm{XRD}$, and the diffraction pattern obtained is shown in Figure $8(\mathrm{~b})$. Essentially, diffraction peaks for graphite, $\mathrm{KC}_{8}$, $\operatorname{SDS}\left(\right.$ at $2 \theta=2.5^{\circ}, 5.0^{\circ}, 7.5^{\circ}$, and $15.0^{\circ}$ ), $\mathrm{K}_{2} \mathrm{O}$, and $\mathrm{KO}_{2}$ were not detected. It was assumed that $\mathrm{K}_{2} \mathrm{O}$ and $\mathrm{KO}_{2}$ were removed as $\mathrm{KOH}$ (as water-soluble SDS) during the hot water wash. The number of exfoliated graphene layers was so low that graphite diffraction peaks were also not detected. However, diffraction peaks for graphite were detected when the SDS was not used (i.e., the PF8 $-\mathrm{KC}_{8}-\mathrm{H}_{2} \mathrm{O}-\mathrm{H}_{2} \mathrm{O}$-rins sample). From these differences in the XRD patterns, it was concluded that the SDS stabilized the exfoliated graphene and prevented restacking.

Schlögl and Boehm [11] reported that $\mathrm{KC}_{8}$ remained after treatment with water. However, an excess of water (water: $\mathrm{KC}_{8}=50 \mathrm{~cm}^{3}: 0.4 \mathrm{~g}$ ) was used in that experiment, resulting in rapid reaction of the potassium and water at the edges of the graphene layers. The hydrogen gas generated 


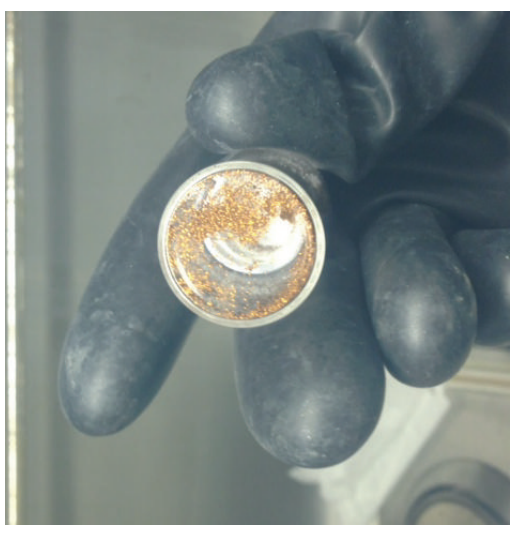

(a)

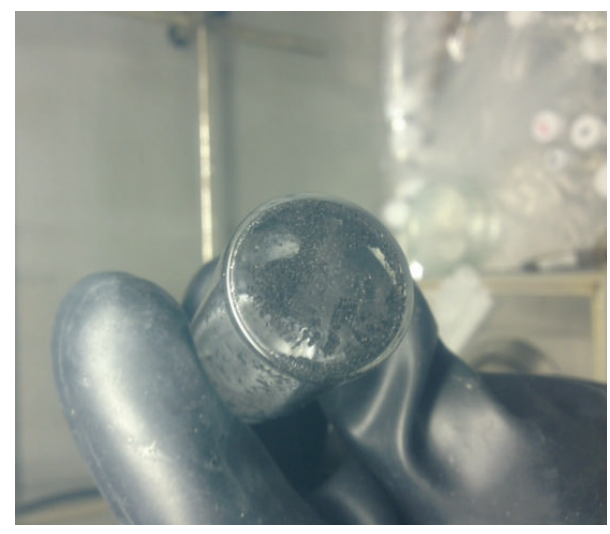

(b)

Figure 4: The appearance of $\mathrm{PF} 8-\mathrm{KC}_{8}$ (a) and $\mathrm{PF} 8-\mathrm{KC}_{8}-\mathrm{H}_{2} \mathrm{O}$ (b).

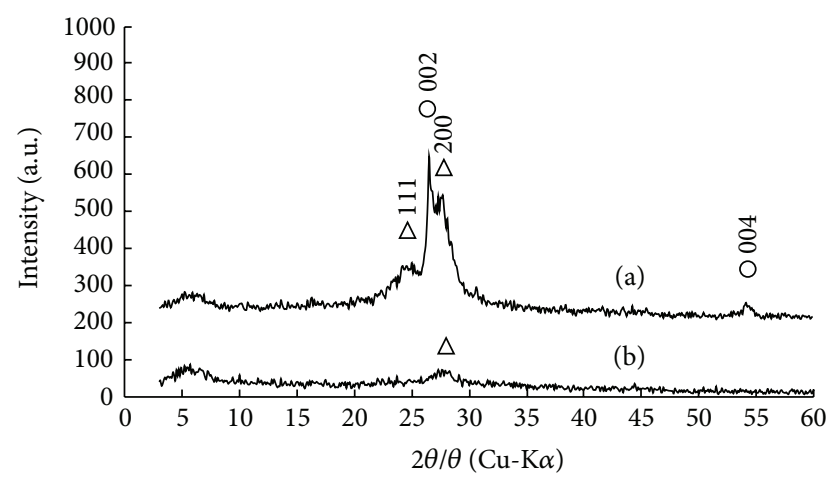

O Graphite

$\triangle \mathrm{K}_{2} \mathrm{O}$

Figure 5: XRD pattern of (a) $\mathrm{SN} 100-\mathrm{KC}_{8}-\mathrm{H}_{2} \mathrm{O}$ and (b) PF8- $\mathrm{KC}_{8}$ $\mathrm{H}_{2} \mathrm{O}$.

at these edges would have blocked further reaction between the potassium and water, resulting in retention of the $\mathrm{KC}_{8}$ structure in the interior of the treated sample.

Finally, the PF8- $\mathrm{KC}_{8}-\mathrm{H}_{2} \mathrm{O}$-SDS-rins sample was observed via Raman spectroscopy, and the spectrum obtained is shown in Figure 9. The D band at $1345 \mathrm{~cm}^{-1}$ was attributed to PF8 exfoliated graphite, which has many graphite defects (see the AFM data in Figure 6). Notably, however, the $\mathrm{I}_{\mathrm{G}} / \mathrm{I}_{\mathrm{G}^{\prime}}$ ratio for the $G$ and $\mathrm{G}^{\prime}$ bands at $1581 \mathrm{~cm}^{-1}$ and $2713 \mathrm{~cm}^{-1}$, respectively, was found to be 1.61 , because an $\mathrm{I}_{\mathrm{G}} / \mathrm{I}_{\mathrm{G}^{\prime}}$ ratio greater than 1.3 suggests the presence of a few graphene layers [12]. This result indicates that there were a few graphene layers in the PF8- $\mathrm{KC}_{8}-\mathrm{H}_{2} \mathrm{O}$-SDS-rins sample. Therefore, it can be concluded that the intercalated potassium reacted with the water to generate hydrogen gas, as shown in (1) and that the $\mathrm{H}_{2}$ gas then degraded the stage structure and exfoliated a few graphene layers. In addition, the use of a surface-acting agent

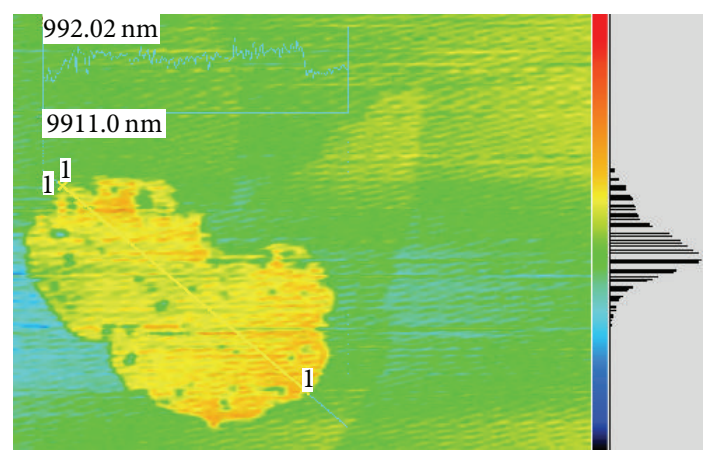

Figure 6: AFM data of PF8- $\mathrm{KC}_{8}-\mathrm{H}_{2} \mathrm{O}-\mathrm{SDS}$.

in the water solution stabilized the exfoliated graphene layers and prevented restacking.

\section{Conclusion}

Using the exfoliated graphite powder as a starting material, exfoliated graphene was prepared via the hydroxylation of a potassium-graphite intercalation compound $\left(\mathrm{KC}_{8}\right)$. When a small amount of water was dropped onto the PF8- $\mathrm{KC}_{8}$ sample in an oxygen-free atmosphere, agglomerated graphene was obtained. The agglomerated graphene was subsequently dispersed via ultrasonic treatment in a water solution containing SDS as an anionic surface active agent. A few drops of this dispersion were diluted for AFM analysis, and the remainder was rinsed with hot water using a microporous filter to remove the SDS and oxidized potassium for SEM, XRD, and Raman spectroscopy. The sample for the AFM was found to be composed of a few layers of graphene which have an area of $20-100 \mu \mathrm{m}^{2}$ and thickness of $1.7 \mathrm{~nm}$. The sample remaining on the filter was analyzed via SEM, XRD, and Raman spectroscopy, and it was found to be soft and thinner than the case of using the natural graphite as a starting 


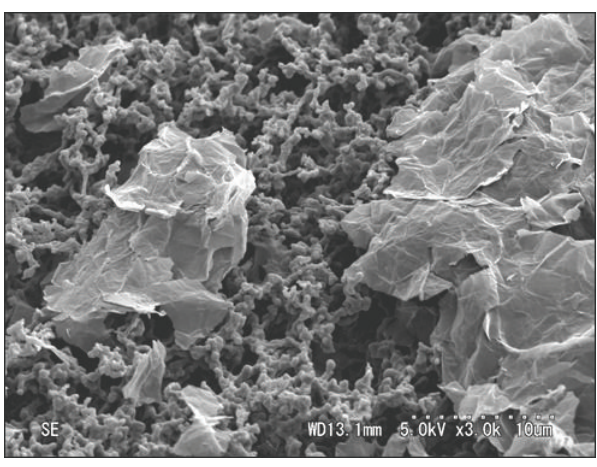

(a)

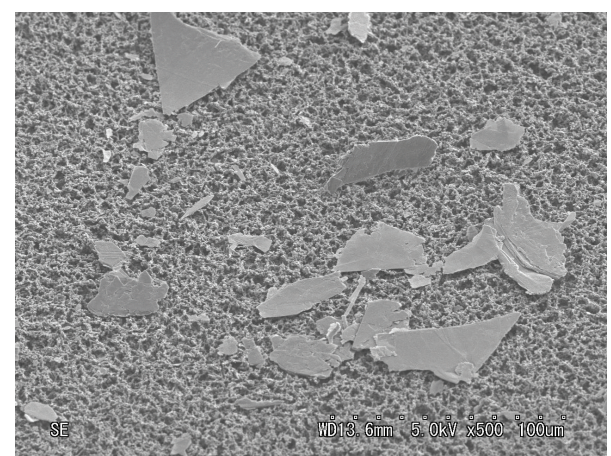

(b)

Figure 7: (a) SEM of PF8- $\mathrm{KC}_{8}-\mathrm{H}_{2} \mathrm{O}$-SDS-rins on a nitrocellulose filter; (b) SEM of SN100- $\mathrm{KC}_{8}-\mathrm{H}_{2} \mathrm{O}$-SDS-rins on a nitrocellulose filter.

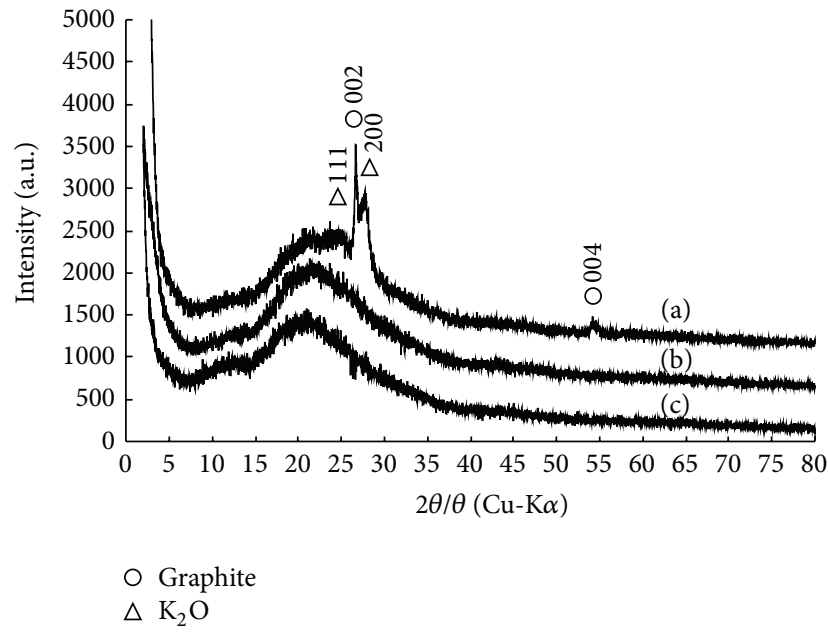

FIGURE 8: XRD pattern of $\mathrm{SN} 100-\mathrm{KC}_{8}-\mathrm{H}_{2} \mathrm{O}$-SDS-rins on a nitrocellulose filter (a), $\mathrm{PF} 8-\mathrm{KC}_{8}-\mathrm{H}_{2} \mathrm{O}$-SDS-rins on a nitrocellulose filter (b) and a nitrocellulose filter only $(\mathrm{c})$.

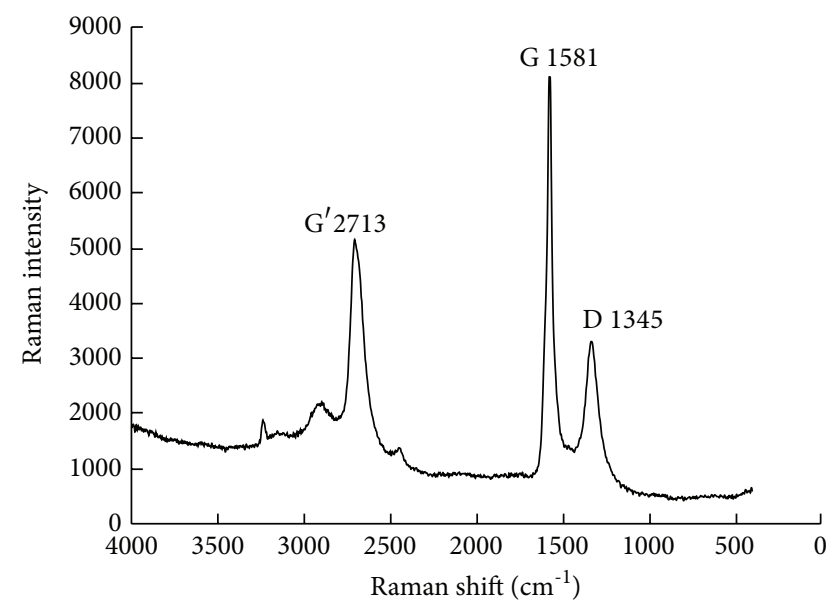

FIGURE 9: Raman pattern of $\mathrm{PF} 8-\mathrm{KC}_{8}-\mathrm{H}_{2} \mathrm{O}$-SDS-rins on a nitrocellulose filter. material by the SEM, and the pattern of graphite was not appeared by the XRD. From discussion of $\mathrm{I}_{\mathrm{G}} / \mathrm{I}_{\mathrm{G}^{\prime}}$ ratio for the $G$ and $G^{\prime}$ bands, the presence of few layers graphene was suggested.

\section{Conflict of Interests}

The authors declare that there is no conflict of interests regarding the publication of this paper.

\section{References}

[1] S. Bae, H. Kim, Y. Lee et al., "Roll-to-roll production of 30-inch graphene films for transparent electrodes," Nature Nanotechnology, vol. 5, no. 8, pp. 574-578, 2010.

[2] W. S. Hummers Jr. and R. E. Offeman, "Preparation of graphitic oxide," Journal of the American Chemical Society, vol. 80, no. 6, p. 1339, 1958.

[3] M. Hirata, T. Gotou, S. Horiuchi, M. Fujiwara, and M. Ohba, "Thin-film particles of graphite oxide 1: high-yield synthesis and flexibility of the particles," Carbon, vol. 42, no. 14, pp. 2929-2937, 2004.

[4] K. Ueno, "Fabrication of graphene by chemical methods and its application to organic semiconductor devices," The Journal of the Vacuum Society of Japan, vol. 53, no. 2, pp. 73-79, 2010 (Japanese).

[5] Y. Takahashi and N. Akuzawa, TANSO No. 111, 171-178, 1982, (Japanese).

[6] N. Akuzawa and R. Matsumoto, "A technical guideline for preparing alkali metal-graphite intercalation compoundsvapor phase and solid phase reactions," TANSO, no. 230, pp. 373-378, 2007 (Japanese).

[7] N. Akuzawa, "Reactivity of alkali metal-graphite intercalation compounds," TANSO, vol. 2011, no. 248, pp. 96-101, 2011 (Japanese).

[8] T. Wada, T. Yasutake, A. Nakasuga, T. Kinumoto, T. Tumura, and M. Toyoda, "Preparation of few-layer graphene by the hydroxylation of potassium-graphite intercalation compound," TANSO, no. 262, pp. 59-62, 2014 (Japanese).

[9] L. M. Viculis, J. J. Mack, and R. B. Kaner, "A chemical route to carbon nanoscrolls," Science, vol. 299, no. 5611, p. 1361, 2003. 
[10] N. R. Tummala, B. P. Grady, and A. Striolo, "Lateral confinement effects on the structural properties of surfactant aggregates: SDS on graphene," Physical Chemistry Chemical Physics, vol. 12, no. 40, pp. 13137-13143, 2010.

[11] R. Schlögl and H. P. Boehm, "The reaction of potassiumgraphite intercalation compounds with water," Carbon, vol. 22, no. 4-5, pp. 351-358, 1984.

[12] Z. S. Wang, R. Zhang, Z. D. Zhang et al., "Raman spectroscopy of few-layer graphene prepared by $\mathrm{C}_{2}-\mathrm{C}_{6}$ cluster ion implantation," Nuclear Instruments and Methods in Physics Research B, vol. 307, pp. 40-42, 2013. 

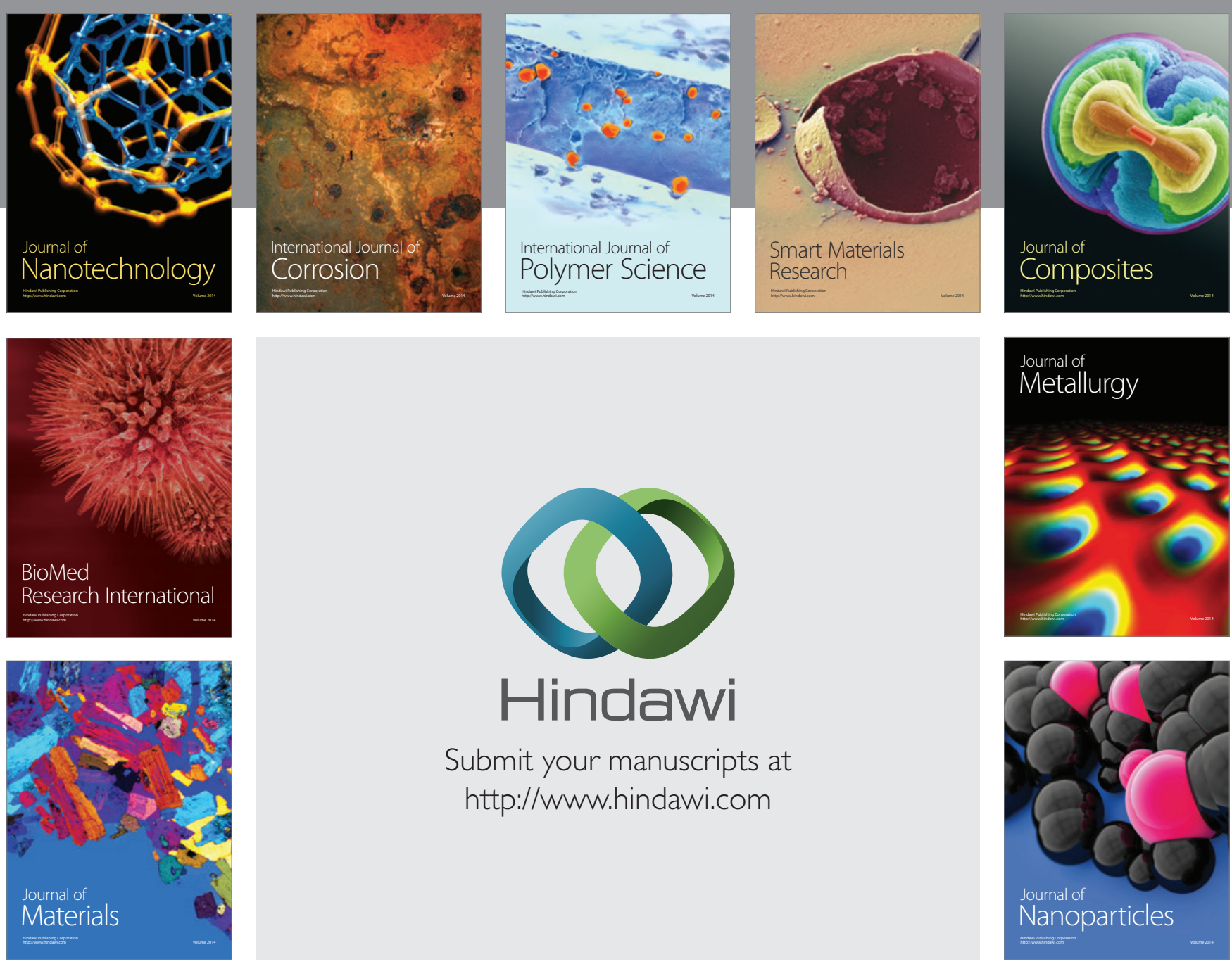

Submit your manuscripts at http://www.hindawi.com
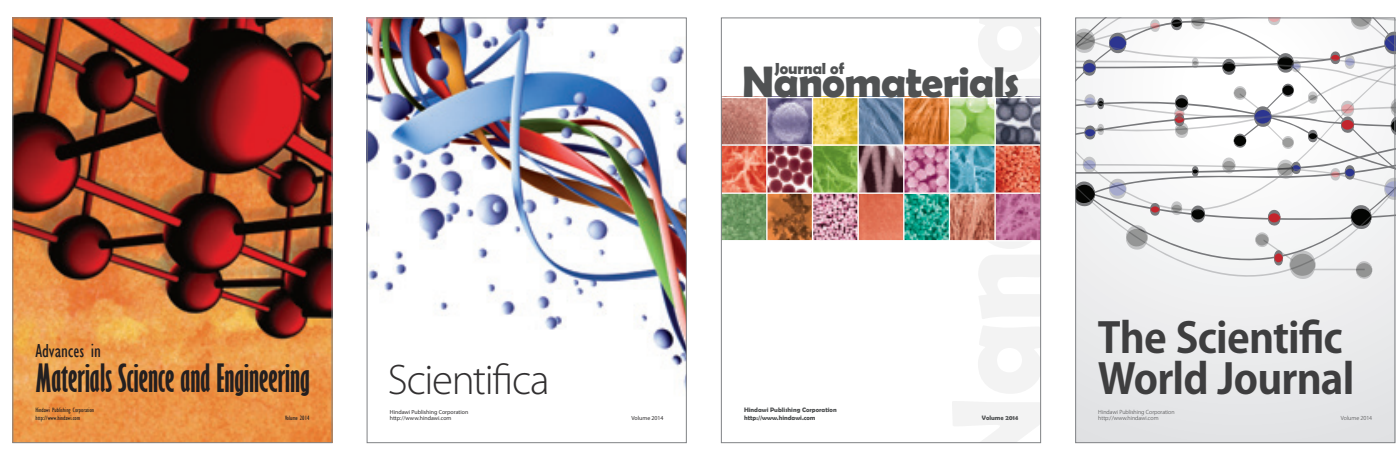

\section{The Scientific World Journal}
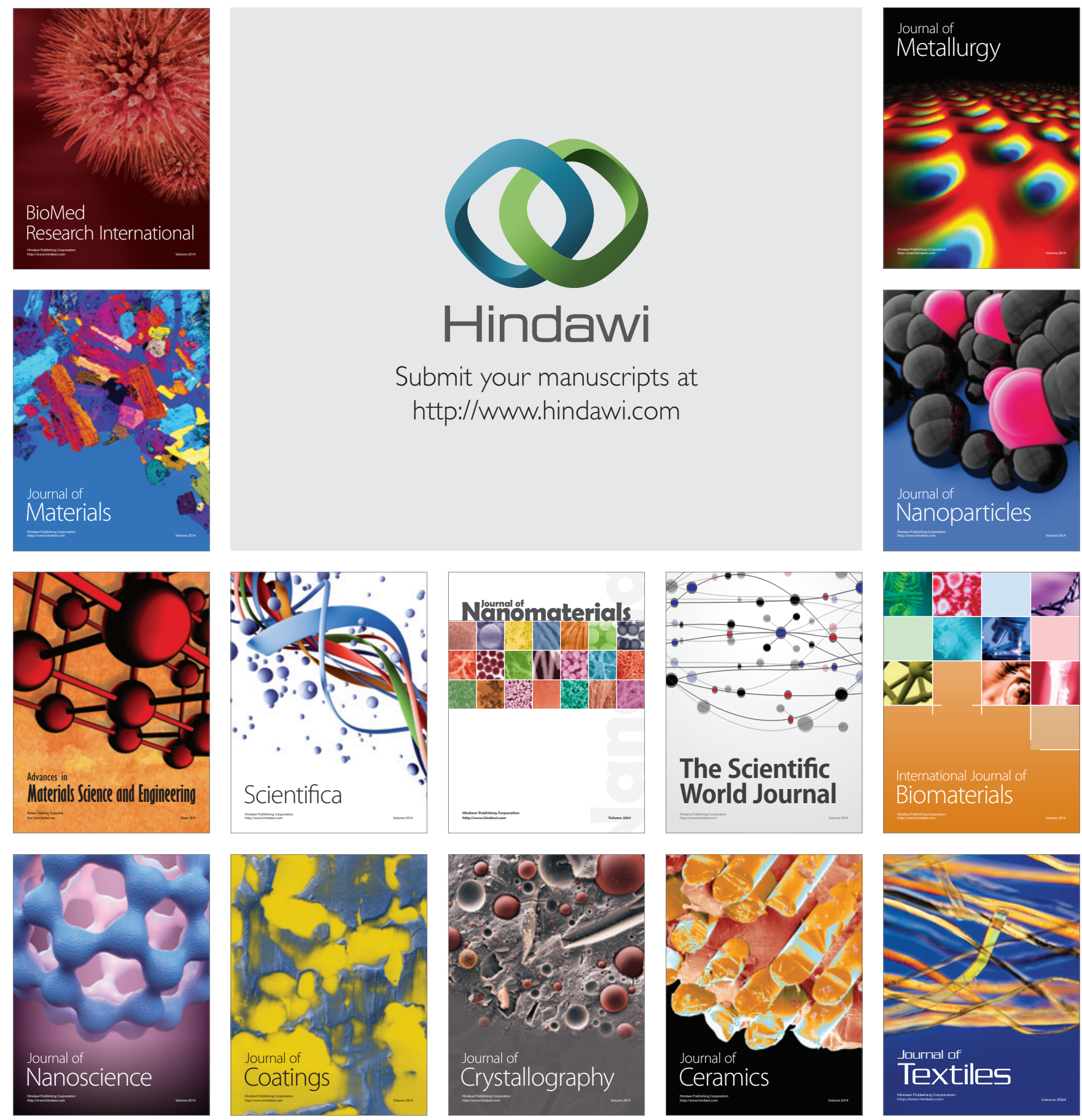